\title{
AVALIAÇÃO DOS MEIOS DE CULTURA UTILIZADOS TANTO PARA OCRESCIMENTO BACTERIANO COMO PARA PRODUÇÃO DA DEXTRANA- SACARASE A PARTIR DE Leuconostoc pseudomesenteroides
}

\author{
$\underline{\text { Tainah Reis de Souza Teixeira }}^{1}$; Cláudio Roberto Nobrega Amorim²;
}

1. Bolsista PROBIC/UEFS, Graduando em Ciências Biológicas, Universidade Estadual de Feira de Santana, e-mail: tainahreeis.bio@outlook.com

2. Orientador, Departamento de Ciências Biológicas, Universidade Estadual de Feira de Santana, e-mail: amorim71@ig.com.br

PALAVRAS-CHAVE: Leuconostoc, Dextrana-Sacarase, meio de cultura.

\section{Introdução:}

A diversidade estrutural dos exopolissacarídeos aliada à baixa toxicidade e biodegradabilidade explica o seu enorme potencial biotecnológico (KUMAR, 2007), mais especificamente os produzidos por bactérias são vantajosos devido à alta produtividade, invariabilidade sazonal e geográfica, e condições controláveis da produção, além de serem mais estáveis e passíveis de modificação, por exemplo, através da engenharia genética (SOUZA \& GARCIA-CRUZ 2004); (KULSHRESHTHA, 2013).

Exopolissacarídeos de origem bacteriana têm despertado o interesse das mais variadas indústrias podendo ser utilizados pra várias especialidades. A dextrana é um dos exopolissacarídeos produzida por bactérias dos gêneros Leuconostoc, Lactobacillus $e$ Streptococcus, pela ação da enzima dextrana-sacarase, que é ativada pela sacarose (com exceção das espécies do gênero Streptococcus). A enzima utiliza a sacarose como substrato e polimeriza a dextrana. Este homopolissacarídeo possui alta massa molecular (107 a $108 \mathrm{kDa})$, é formado por resíduos de D-glicose conectados por ligações glicosídicas $(\alpha-1,6)$ na cadeia linear, e nas ramificações ligações do tipo $\alpha-(1,2), \alpha-(1,3)$ e $\alpha-(1,4)$ (SANDFORD, 1979). A Dextrana tem grade importância industrial e é largamente utilizada como aditivo, espessante, estabilizante e emulsificante em produtos alimentícios, cosméticos, fabricação de tintas, imobilizante em processos cromatográficos e também na área médica, agindo como anticoagulante e extensor de plasma, biossensor, antitrombótico, dentre outros (BHAVANI \& NISHA, 2010).

Muito empenho tem sido aplicado ao longo dos anos para desenvolver metodologias eficazes, rápidas e com menor custo para a produção das dextranas (NIGAM et al., 2005); (VETTORI et al., 2012); (NAESSENS et al., 2005). Assim, os estudos que se voltam para a dextrana-sacarase têm um papel fundamental neste processo. Dentre os benefícios desta abordagem, pode-se frisar a redução com gastos para manter a colônia, facilidade na separação final do produto com alto grau de pureza, além da possibilidade de reaproveitamento da enzima nas etapas da produção (CHIELLINI et al., 2001). Dessa maneira, o presente estudo se justifica, portanto, em otimizar as condições de produção da dextrana-sacarase através das bactérias láticas produtoras de exopolissacarídeos isoladas da região, afim de verificar qual o melhor meio a ser utilizado e as condições mais favoráveis 
para que estas cresçam mais rapidamente consequentemente obtendo eficiência na aquisição deste exopolissacarídeo de grande interesse industrial.

\section{Materiais de Métodos:}

Foram utilizadas neste trabalho amostras bacterianas de Leuconostooc fornecidas pela

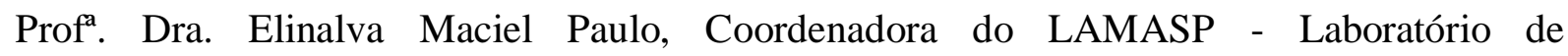
Microbiologia Aplicada à Saúde Pública da Universidade Estadual de Feira de Santana (UEFS). Tais amostras foram triadas e isoladas conforme a metodologia descrita por PAULO et al. (2012), a partir de produtos alimentícios industrializados (laticínios) e vegetais. As amostras foram cultivas em treze meios diferentes testadas em diferentes $\mathrm{pH}(5,0 ; 5,5 ; 6,0$; $6,5)$ e diferentes temperaturas $\left(25^{\circ} \mathrm{C} ; 30^{\circ} \mathrm{C} ; 35^{\circ} \mathrm{C}\right)$.

A atividade da enzima dextrana-sacarase foi detectada indiretamente, através da medição da taxa de produção do açúcar redutor D-frutose a partir da sacarose. O ensaio da dextrana foi realizado em $1 \mathrm{ml}$ de uma mistura de reação em tampão de acetato de sódio 20 $\mathrm{mM}$, pH 5,4, contendo $146 \mathrm{mM}$ de sacarose (5\%) e utilizando o sobrenadante livre de células (10 a $20 \mu \mathrm{l}$ ) como fonte de enzimas. A mistura da reação será incubada a $30^{\circ} \mathrm{C}$ durante 15 min. A atividade enzimática foi mensurada através da estimativa do açúcar redutor libertado, pelo método do DNS (3,5 DinitroSalicilato). Alíquotas $(0,2 \mathrm{ml})$, a partir da mistura de reação foram analisadas para a concentração do açúcar redutor. A absorbância foi medida na faixa de $500 \mathrm{~nm}$, utilizando um espectrofotômetro de UV visível contra um padrão de D-frutose. Uma unidade (U) de atividade da dextrana-sacarase definida será a quantidade de enzima que libera $1 \mu \mathrm{mol}$ de açúcar redutor por min a $30^{\circ} \mathrm{C}$ em tampão de acetato de sódio $20 \mathrm{mM}, \mathrm{pH} 5,4$. O teor total da proteína do sobrenadante livre de células foi estimado pelo método de Lowry e colaboradores (1951), utilizando a albumina bovina sérica como padrão (SUMNER, 1935); (CONTIERO, 2004).

\section{Resultados e Discussão:}

Neste estudo as amostras bacterianas na forma liofilizada de Leuconostoc pseudomesenteroides R2, fornecidas pela Dr. Elinalva Maciel, foram reativadas num procedimento de três passos, que consistiu em i) a inoculação de $15 \mathrm{ml}$ de solução salina (10\% cloreto de sódio); ii) a inoculação em $5 \mathrm{~mL}$ de meio de cultura MRS (suplementado com sacarose) e iii) a inoculação em $10 \mathrm{~mL}$ de MRS. Estes passos foram realizados sequencialmente a $28^{\circ} \mathrm{C}$ com a duração de 24 horas cada um. As amostras bacterianas reativadas foram inoculadas para teste em 13 diferentes composições de meios de cultura em diferentes $\mathrm{pH}(5,0 ; 5,5 ; 6,0 ; 6,5)$ e diferentes temperaturas $\left(25^{\circ} \mathrm{C} ; 30^{\circ} \mathrm{C} ; 35^{\circ} \mathrm{C}\right)$. A Tabela 1 mostra os resultados da análise da atividade enzimática utilizando-se o ácido 3,5dinitrosalicílico (DNS) baseado no método de Miller (1959). Para a determinação do conteúdo protéico total foi utilizado o método Bradford (1976) utilizando-se o soro albumina bovina como padrão. As leituras foram efetuadas no espectrofotômetro UV/VIS modelo Varian, no comprimento de onda $595 \mathrm{~nm}$ obtendo os valores tabelados abaixo: 
Tabela 1.Quantidade de enzima produzida a $25^{\circ} \mathrm{C}, 30^{\circ} \mathrm{C}$ e $35^{\circ} \mathrm{C}$, em U/ml

\begin{tabular}{|c|c|c|c|c|c|c|c|c|c|c|c|c|}
\hline & \multicolumn{3}{|c|}{ pH 5,0 } & \multicolumn{3}{|c|}{ pH 5,5 } & \multicolumn{3}{|c|}{ pH 6,0 } & \multicolumn{3}{|c|}{ pH 6,5 } \\
\hline & $25^{\circ} \mathrm{C}$ & $30^{\circ} \mathrm{C}$ & $35^{\circ} \mathrm{C}$ & $25^{\circ} \mathrm{C}$ & $30^{\circ} \mathrm{C}$ & $35^{\circ} \mathrm{C}$ & $25^{\circ} \mathrm{C}$ & $30^{\circ} \mathrm{C}$ & $35^{\circ} \mathrm{C}$ & $25^{\circ} \mathrm{C}$ & $30^{\circ} \mathrm{C}$ & $35^{\circ} \mathrm{C}$ \\
\hline MEIO1 & 79,4 & 78,5 & 71,2 & 73,7 & 73,4 & 70,9 & 69,1 & 67,5 & 62,3 & 89,5 & 86,3 & 80,7 \\
\hline MEIO2 & 87,6 & 86,4 & 83,5 & 81,4 & 82 & 81,7 & 64,8 & 63,6 & 64,6 & 97,3 & 90,6 & 85,5 \\
\hline MEIO3 & 89,6 & 84,7 & 88,4 & 72,6 & 72,6 & 78,3 & 67,9 & 66,4 & 65,2 & 91,5 & 94,9 & 90,3 \\
\hline MEIO4 & 76,2 & 66,7 & 64,0 & 69,5 & 64,9 & 62,5 & 63,7 & 63,2 & 67,1 & 85,6 & 83,7 & 83,3 \\
\hline MEIO5 & 97,4 & 82,8 & 77,3 & 77,8 & 72,5 & 70,7 & 71,1 & 69,6 & 66,9 & 89,2 & 92,8 & 88,2 \\
\hline MEIO6 & 83,2 & 82,7 & 81,5 & 80 & 78,6 & 63,6 & 69,3 & 65,9 & 62,4 & 93,9 & 92,8 & 91,4 \\
\hline MEIO7 & 76,2 & 74,9 & 70,7 & 66,4 & 67,9 & 79,7 & 65,7 & 63,7 & 64,6 & 82,6 & 80,7 & 89,1 \\
\hline MEIO8 & 94,7 & 90,7 & 86,3 & 87,1 & 82,9 & 65,5 & 80,3 & 79,3 & 70,2 & 109,2 & 103,3 & 101,8 \\
\hline MEIO9 & 76,1 & 75,6 & 64,8 & 64,7 & 67,2 & 73,9 & 67,3 & 65,6 & 66,8 & 100,3 & 99,5 & 100 \\
\hline MEIO10 & 86,1 & 84,4 & 81,7 & 73,9 & 70,7 & 65,9 & 79,5 & 78,9 & 70,3 & 102,7 & 100,6 & 93,9 \\
\hline MEIO11 & 70,7 & 68,6 & 64,9 & 65,3 & 66,4 & 66,8 & 63,7 & 63,1 & 62,2 & 97,4 & 95,7 & 90,4 \\
\hline MEI012 & 71,2 & 73,7 & 77,5 & 67,9 & 63,8 & 64,8 & 67,9 & 64,7 & 62,4 & 95,8 & 94,7 & 89,7 \\
\hline MEIO13 & 71,7 & 69,2 & 68,2 & 71 & 70 & 71,9 & 70,8 & 68,4 & 64,8 & 97,3 & 96,8 & 93,1 \\
\hline
\end{tabular}

Baseado nos resultados obtidos as condições otimizadas para a atividade enzimática foram as que o $\mathrm{pH}$ corresponde a $6,5 \mathrm{em}$ condições de temperatura a $25^{\circ} \mathrm{C}$ e a menos favoráveis em pH 6,0 e temperatura a $35^{\circ} \mathrm{C}$.

A avaliação enzimática mostrou altos valores que variam entre 62,2 - 109,2 U.mg-1 , que demonstram a grande expressão de dextrana-sacarase por L. pseudomesenteroides. Dentre os 13 meios avaliados, podemos observar que o meio 8 obteve-se o número mais elevado de enzima produzida $\left(109,2 \mathrm{U}_{\mathrm{mg}}^{-1}\right)$ sob as condições de temperatura a $25^{\circ} \mathrm{C}$ e $\mathrm{pH}$ a $6,5 . \mathrm{Em}$ contrapartida, houve baixa produção enzimática no meio $11\left(62,2 \mathrm{U} \mathrm{mg}^{-1}\right)$ sob as condições de produção enzimática com temperatura aos $35^{\circ} \mathrm{C}$ e pH em 6,0. A tendência de produção de dextrana-sacarase ocorre em valores de $\mathrm{pH}$ e de temperatura mais baixa em comparação com a produção de dextrana por estudos com a enzima a partir de outras fontes como o trabalho de M. Nigam, A. Goyal, and S.S. Katiyar (2005). Resultados mais semelhantes foram encontrados em dextrana-sacarases de Weissella cibaria e L. mesenteroides NRRL B-650, que é utilizado respectivamente $\mathrm{pH} 6,9$ e $\mathrm{pH} 7,0$ e temperatura de $24{ }^{\circ} \mathrm{C}$ e $23{ }^{\circ} \mathrm{C}$.

\section{CONCLUSÃO:}

Baseado nos dados obtidos conclui-se que o meio 8 composto de 4,0 gramas de sacarose, 2,0 gramas de extrato de levedura, 0,001 gramas de $\mathrm{NaCl}, \mathrm{MnSO}_{4}$ e $\mathrm{FeSO}_{4}, 0,002$ 
gramas de $\mathrm{CaCl}_{2}, 0,02$ gramas de $\mathrm{MgSO}_{4} \mathrm{e}$ 2,0 gramas de $\mathrm{KH}_{2} \mathrm{PO}_{4}$ foi o melhor para a obtenção de uma elevada atividade enzimática e as condições otimizadas para essa atividade foram nas quais o $\mathrm{pH}$ corresponde a 6,5 em condições de temperatura a $25^{\circ} \mathrm{C}$.

\section{Referências:}

BHAVANI, A.LAKSHMI; NISHA, J. Dextran - The Polysaccharide With Versatile Uses. International Journal Of Pharma And Bio Sciences. 2010.

CHIELLINI, EMO ET AL. Biomedical Polymers: Sustainable Polymer Science And Technology. ISBN 0-306-46652-X. 2001.

CONTIERO, J. Estudo Da Produção De Dextranasacarase Por Leuconostoc MesenteroidesFt 045 B, Tese de doutorado.Universidade Estadual Júlio de Mesquita Filho, Rio Claro - São Paulo. 2004.

KULSHRESHTHA, SHWETA. Genetically Engineered Microorganisms: A Problem Solving Approach For Bioremediation. Bioremediation \&Biodegradat. V. 4 Is. 4. 2013.

KUMAR, A.S., MODY, K, JHA, B. Bacterial Exopolysaccharides - A Perception. J Basic Microb. 47:103-117. 2007.

M. Nigam, A. Goyal, and S.S. Katiyar: "High yield purification of dextransucrase from Leuconostocmesenteroides NRRL B-512 by phase partitioning." vol. 30, no. 2006, pp. 12-20, 2005.

NAESSENS, M.; WIM SOETAERTAND, A. C. , VANDAMM E. J. eLeuconostoc Dextransucrase And Dextran: Production, Properties And Applications. J. Chem. Technol. Biotechnol., 80, 845-860. 2005.

NIGAM, M.; GOYAL, A.; KATIYAR, S.S. High Yield Purification Of Dextransucrase From LeuconostocMesenteroidesNrrl B-512f By Phase Partitioning .2005.

SANDFORD.Advances In Carbohydrhe Chemistry And Biochemistry, Vol. 36 Exocellular, Microbial Polysaccharides. 1979

SOUZA \& GARCIA-CRUZ. Fermentative Production Of Exocellular Polysaccharides By Bacteria SeminaCiênc. Agrar.,25, 331. 2004.

VETTORI ET AL. Dextran: Effect Of Process Parameters On Production, Purification And Molecular Weight And Recent Applications. Diálogos\&Ciência. 31, 171-186. 2012. 